\title{
Reviews
}

\section{Conceptual History in the Post-Koselleckian Era}

Willibald Steinmetz, Michael Freeden and Javier Fernández-Sebatián (eds.), European Conceptual History in the European Space. Berghahn Books. 2017. 320 pages. ISBN 9781785334825.

\section{Niklas Olsen, University of Copenhagen}

The newly launched book series on European Conceptual History, published by Berghahn Books, is the latest initiative in the ongoing attempt to renew conceptual history as an academic field. "This series", so the web page states, "focuses on the notable values and terminology that have developed throughout European history, exploring key concepts such as parliamentarianism, democracy, civilization, and liberalism to illuminate a vocabulary that has helped to shape the modern world." Three volumes have appeared to date: Parliament and Parliamentarism, European Regions and Boundaries, and Basic and Applied Research. A volume on Democracy in Modern Europe is forthcoming.

Conceptual History in the European Space is meant as the lead volume to this series. It is edited by three well-known scholars in the field - Willibald Steinmetz, Michael Freeden and Javier Fernández Sebastián - and contains ten chapters (plus an introduction and a conclusion) authored by specialist conceptual historians. The aim of the volume is to represent some of the most important theoretical, methodological and thematic contributions to the field in what the introductory chapter, authored by Steinmetz and Freeden, labels the "post-Koselleckian era" (which seems to be the period from around 2000 onwards). The essays are not divided into thematic sections, but address a range of different issues, including temporal, spatial, rhetorical, ideological and linguistic dimensions of conceptual history.

Some of the included texts are derived from research projects and publications that have already become classic contributions to conceptual history. Jörn Leonhard's discussions of the possibilities and pitfalls of the comparative dimension of conceptual history draw on his famous study of the meanings and transfers of the concepts of "liberal" and "liberalisms" into various European languages in the eighteenth century. Helge Jordheim's elaboration of Koselleck's theories of historical times as encapsulated in the catchword "synchronicity of the non-synchronous" into a more detailed framework to ana- 
lyze the conceptual entanglements and transfers that make up the multiple temporal layers of European history rely on his earlier articles on the topic. Kari Palonen's explorations of the specific debate-bound forms of conceptual change, which focus on the rhetoric of concepts in parliamentary debates, and on the different ways of addressing political issues in these debates, is extracted from his large oeuvre addressing these themes. Likewise, Michael Freeden's outline of an approach to the study of political language that emphasizes the essential contestability of language and the interdependent world of concepts have recourse to his many books on this subject.

Other contributions represent more recently initiated research projects and discussions (or discussions that have arguably received less attention in the field). Diana Mishkova and Balázs Trencsényi connect conceptual history to the spatial turn by exploring historical practices of giving names to nations and regions in central and southeastern Europe. With the Nordic countries as his example, Henrik Stenius proposes a "core-periphery hypothesis", which outlines a set of ideal type responses available for the speakers of peripheral languages when confronted with speakers of major central European languages.

Finally, continuing discussions that he has initiated elsewhere on the temporal frameworks of conceptual history, in an especially valuable article, Willibald Steinmetz deconstructs the widespread idea that conceptual history is inextricably bound to investigations of the Sattelzeit. In doing so, he suggests a new research program for the field - arguing that the four processes characterizing the Sattlezeit (politicization, ideologization, democratization and the entiming of concepts) are not bound to a specific era, but are repeatable and reversible phenomena found in all epochs of European history. Steinmetz makes the same claim about what he calls the three processes of vernacularization, nationalization and anglicization of concepts. According to Steinmetz, a research program stressing the repetitions and reverse movements of all of these seven processes is better equipped to account for the variety of European experiences without losing sight of the necessity to formulate hypothesis that possess significance beyond single case studies. Steinmetz's essay stands out by offering an entirely new and comprehensive set of theoretical starting points and platforms for further research.

The inspiration of Koselleck runs through all the essays in the volume, but they do not treat his work as dogma. Instead, they elaborate on unexplained catchwords, blind spots and deficiencies; merge theories and methods from "classic" conceptual history with approaches from other fields; and update the analytical framework to explore questions, themes and problems derived from present day concerns. As such, the determination to renew the field and the insistence on analytical plurality appear as key characteristics in the so-called "post-Koselleckian" age. These are features, one might add, that Koselleck himself would certainly have applauded. 
Indeed, the editors have done the academic community a great favor by collecting a selection of insightful, well-written and concise contributions in one volume, though it should be added that the volume seems to be primarily for scholars within the field, as it arguably requires a certain knowledge of specific traditions, debates and developments to understand what is at stake in many of the essays. Next to setting out numerous issues that have contributed to the renewal of the field in the past two decades, the volume also serves as a platform for further investigation and innovation. It will be interesting to see where projects in conceptual history go from here, and how new studies will relate to the calls and challenges presented in this book.

Surely, readers of the book will feel prompted to suggest further places where the field can concentrate its efforts and broaden horizons. Here I will briefly point to three such places.

1 In order to retain the political urgency and relevance that characterized Koselleck's work, it might be fruitful to offer news interpretation of the contemporary age and its political challenges, for example by addressing themes such as populism, climate issues or the economy. While outsiders to the field, such Janet Roitman (Anticrisis) have taken up the challenge to interpret the present age using tools from conceptual history, scholars within the field have arguably somewhat neglected to keep this tradition alive.

2 A thorough discussion of how we are to understand and study political language in the twentieth history is another site at which scholars can renew the field and keep it attractive vis-à-vis neighboring fields. Willibald Steinmetz and Jan-Werner Müller began this discussion (and in strikingly similar ways) in Political Languages in the Age of Extremes and Contesting Democracy respectively. Moreover, Christian Geulen took it up in his plea to write a history of twentieth-century German basic concepts, which received a fruitful reply by Steinmetz. However, as neighboring fields, such as political theory, are now taking an interest in the topic, and conceptual historians are moving their empirical analysis into the twentieth century, there remains a need for further theoretical discussion and methodological innovation in the field.

3 The cultural and social sciences are currently under the spell of globalism, and to link up to current disciplinary developments, a stronger embrace of the global perspective seems warranted. Scholars like Magrit Pernau have already pushed the field in this direction by co-editing a volume on Global Conceptual History and by co-authoring volumes such as Civilizing Emotions that analyses the meaning, spread and translation of concepts across many different languages. However, while competing fields, such as intellectual history, were quick to incorporate the global in mainstream re- 
search, this has arguably not yet been the case in conceptual history. In line with this, limiting the volume reviewed here to the European conceptual space arguably does a disservice to the many essays in the collection that in fact sketch several possibilities and perspectives for a more globally oriented conceptual history.

These suggestions for concentrating efforts and broadening horizons are meant more as input to a general discussion of the field than as critique of European Conceptual History in the European Space. Indeed, the volume is to be strongly recommended not only for offering usable insights on conceptual history for one specific project, but also for providing inspiration more broadly. 